\title{
Maternal incarceration, child protection, and infant mortality: a descriptive study of infant children of women prisoners in Western Australia
}

\author{
Caitlin McMillen Dowell $^{1 *}$, Gloria C. Mejia ${ }^{1}$, David B. Preen ${ }^{2}$ and Leonie Segal ${ }^{1}$
}

\begin{abstract}
Background: There are no population statistics collected on a routine basis on the children of prisoners in Australia. Accordingly, their potential vulnerability to adverse outcomes remains unclear. This study draws on linked administrative data to describe the exposure of children aged less than 2 years to maternal imprisonment in Western Australia, their contact with child protection services, and infant mortality rates.

Results: In Western Australia, 36.5 per 1000 Indigenous $(n=804)$ and 1.3 per 1000 non-Indigenous $(n=395)$ children born between 2001 and 2011 had mothers imprisoned after birth to age 2 years. One-third of infants' mothers had multiple imprisonments (maximum of 11). Nearly half (46\%) of prison stays were for $\leq 2$ weeks, $12 \%$ were between 2 and 4 weeks, 14\% were for 1-3 months, and 28\% were longer than three months. Additionally, 17. 4 per 1000 Indigenous $(n=383)$ and 0.5 per 1000 non-Indigenous $(n=150)$ children had mothers imprisoned during pregnancy. Half of the children with a history of maternal incarceration in pregnancy to age 2 years came into contact with child protection services by their second birthday, with 31\% of Indigenous and 35\% of non-Indigenous children entering out-of-home care. Rates of placement in care were significantly higher for Indigenous children (Relative Risk (RR) 27.30; 95\% 19.19 to 38.84; $p$ <.001) and for non-Indigenous children (RR 110.10; 95\%Cl 61.70 to 196.49; $p<.001$ ) with a history of maternal imprisonment compared to children of mothers with no corrections record. Infant mortality for children whose mothers were imprisoned up to 5 years before birth or within their first year after birth was higher than for children of mothers with no corrections record for both Indigenous (RR 2.36; 95\%Cl 1.41 to $3.95 ; p=.001$ ) and non-Indigenous children (RR 2.28; 95\% Cl 0.75 to $6.97 ; p=.147$ ).
\end{abstract}

Conclusions: This study highlights the particular vulnerability of children whose mothers have been incarcerated and the importance of considering their needs within corrective services policies and procedures. Prison may present an opportunity to identify and work with vulnerable families to help improve outcomes for children as well as mothers.

Keywords: Women, Children, Prisoners, Infant mortality, Child protection, Vulnerable populations

\section{Background}

Children of prisoners are highly vulnerable. Prisoners experience elevated rates of adversity including mental illness, domestic violence, substance use disorders, poverty, homelessness, racism and discrimination (Abbott, Magin, \& Hu, 2016; Department of

\footnotetext{
* Correspondence: caitlin.dowell@mymail.unisa.edu.au

${ }^{1}$ Health Economics and Social Policy Group, Centre for Population Health Research, Sansom Institute, School of Health Sciences, University of South Australia, GPO Box 2471, Adelaide, SA 5001, Australia

Full list of author information is available at the end of the article
}

Corrective Services, 2009; Friestad, Ase-Bente, \& Kjelsberg, 2012). These adverse experiences within a family environment are known to increase the risk of poor outcomes for children, particularly in the early years of infancy (Brown, Anda, Tiemeier, Felitti, Edwards, Croft, \& Giles, 2009). Studies have found children with incarcerated parents experience a range of issues such as poor developmental outcomes, behavioural problems, educational difficulties, and increased mortality (Aaron, \& Dallaire, 2010; Byrne, Goshin, \& Joestl, 2010; Dallaire, Zeman, \& Thrash, 2015; Rud, Van Klaveren, Groot, \& 
Maassen van den Brink, 2014; Wildeman, Andersen, Lee, \& Karlson, 2014). Much of the literature on children of prisoners has been conducted within the United States, United Kingdom and Europe (Murray, Bijleveld, Farrington, \& Loeber, 2014). There is comparatively less known about the experience of children in other countries, including Australia. There is also relatively little evidence available on children of prisoners at a population level.

Within Australia, and beyond, there is no routine reporting of the prevalence of children affected by parental incarceration, nor their health or welfare (Dennison, Stewart, \& Freiberg, 2013). Infant mortality is the most significant adverse outcome that can be experienced and is a strong marker of disadvantage and represents a measure of the health of a population (Reidpath, \& Allotey, 2003). There is a lack of information on infant mortality outcomes for women prisoners, as distinct from imprisoned fathers, due to their relatively smaller numbers (Wildeman, 2012).

Child protection system contact is also an important measure of child welfare. Children with a history of placement in out-of-home care are at increased risk for a range of ongoing difficulties including mental illness, behavioural problems and poor school performance (Maclean, Taylor, \& O’Donnell, 2016; Osborn, Delfabbro, \& Barber, 2008). In addition, information on the characteristics of children's exposure to parental incarceration is not readily available. There is no reporting on such characteristics as the duration and frequency of parental prison stays, or on the classification of parental offences. This information is important for establishing the health status and service needs of children of prisoners, and to inform future research priorities.

In the absence of formal population surveillance, data linkage provides a means for accurately describing the prevalence and characteristics of children of prisoners. Data linkage connects information relating to individuals within defined populations across multiple collections of data which are routinely recorded by government services and departments for primarily administrative purposes, such as hospital admission data or records of births, deaths and marriages (Holman, Bass, Rouse, \& Hobbs, 1999). Data linkage can provide retrospective coverage of entire populations of interest, while maintaining the confidentiality of individuals, making it highly suitable for investigating marginalised groups such as the prisoner population, and rare outcomes such as infant mortality.

This study draws on linked data to provide key descriptive statistics for the population of infant children of women prisoners in Western Australia. Infants are a priority population given their vulnerability and unique developmental considerations. Infants have an absolute reliance on caregivers for their basic needs, lack communication skills, and have less structured contact with community services, such as schooling, where at-risk individuals may be identified. Experiences of adversity during pregnancy and infancy have significant and long-term consequences for child health and development. Exposure of the fetus during pregnancy or of the infant after birth to factors such as poor nutrition and maternal alcohol and drug abuse, domestic violence, and maternal stress has been shown to result in poor health outcomes including low birth weight, infant mortality and developmental delay (McMillen \& Robinson 2005; Heindel, \& Vandenberg, 2016; Latendresse et al., 2015). Women prisoners have increased risk of poor pregnancy outcomes including low birth weight infants when compared to women in the general community, as well an increased risk of disrupted attachment with their infants (Knight, \& Plugge, 2005; Poehlmann, 2005). Despite their vulnerability, it is not known with any certainty how many Australian children experience the imprisonment of their mother in pregnancy or infancy, or the degree to which infants with a history of maternal imprisonment experience higher rates of mortality or child protection contact than infants in the general community.

There are also limited data on the infant children of Australian Indigenous women prisoners, despite their overrepresentation in the prison population. In Western Australia, for example, Indigenous peoples represent $4 \%$ of the general population but $46 \%$ of the female prison population (Australian Bureau of Statistics (ABS), 2016; ABS, 2011). Indigenous children are also overrepresented in the Australian child protection system. Similarly, Indigenous peoples in Australia experience poorer pregnancy outcomes compared with non-Indigenous mothers, and while infant mortality rates have improved across time for both Indigenous and non-Indigenous populations, a racial disparity remains (Council of Australian Governments (COAG) 2016). This reflects the high levels of disadvantage and discrimination experienced by Indigenous peoples in Australia stemming from the historical and continuing impacts of colonisation, such as land dispossession, racism, and the forced removal of children from their families (COAG, 2009).

Accordingly this study will provide a description of the population of infant children of Western Australian women prisoners including details of the characteristics of exposure of infant children (aged less than 2 years) to maternal imprisonment, as well as measuring child protection system contact and infant mortality rates for the population.

\section{Methods}

\section{Aims}

This study draws on whole-population linked administrative data to examine maternal incarceration exposure, child protection system contact, and mortality rates for infant children of Western Australian women prisoners.

Aim 1: To describe the features of maternal incarceration exposure including the proportion of women prisoners who are pregnant; the prevalence of children exposed to maternal incarceration between birth and 
before age-2; and offence type and length and frequency of maternal imprisonments for children between birth and before age- 2 .

Aim 2: To describe contact with the child protection system before 2 years of age for children whose mothers have a record of imprisonment during pregnancy or before the child's second birthday and for children whose mothers have no corrections record.

Aim 3: To determine infant mortality rates for children of women with a history of imprisonment 5 years before birth or within their first year after birth and for children whose mother had no contact with corrective services.

\section{Data sources}

Data were obtained through the Western Australian Data Linkage System (WADLS). The WADLS uses highly accurate computerised probabilistic matching with clerical review to create linkages between administrative data collections across a range of Western Australian government departments and services (Holman et al., 1999). For the present study, records were extracted from the Midwives Notifications System, Birth Registrations, Death Registrations, Department of Justice, and Department of Communities: Child Protection and Family Support data collections. These are all State-wide and statutory data collections with good coverage of the Western Australian population.

The Birth Registration and Midwives Notifications System data provides social and demographic characteristics of mothers and children at time of birth. Death data includes all deaths registered in Western Australia. The Department of Justice data collections include all custodial records for offenders held in Western Australian prisoners or under supervision of the Department on communitybased correctional orders. The Department of Communities: Child Protection and Family Support data includes all reports of concerns for child welfare made to the child protection system and the details of investigations, protection applications and orders as well as placements in out-of-home care.

\section{Study population}

The study population was drawn from a retrospective longitudinal cohort study of all children born in Western Australia between 1985 and 2011 whose biological mother was imprisoned at least once between their date of birth and 18th-birthday, identified using the Midwives Notification System and Registry of Births in conjunction with linked Department of Justice prison data. For a description of the full cohort see Dowell, Preen, and Segal (2017). The cohort study included a randomly sampled comparison group of children whose mother had no record of imprisonment from their birth to their 18th-birthday, which was identified through the same data sources as the cohort and matched 3:1 to cohort children on Indigenous status, age and gender.

The present study focused on a subset of children within the full cohort born from 2001 onwards. This time period was chosen due to substantial changes in the annual prevalence of children affected by maternal incarceration in Western Australia in the 1990s (Dowell et al., 2017). To address the three study aims, we have conducted three separate analyses all of which have slightly different observation periods, and hence different study populations, as summarised in Table 1 . All analyses were stratified by Indigenous status given differences between Australian Indigenous and nonIndigenous populations in terms of their demographic characteristics, health status, sentence type and unique cultural contexts.

To address aim 1, maternal incarceration exposure was described for pregnancy and after birth to before age 2-years separately, because of the different implications of imprisonment for unborn and infant children. The study population included children born 2001-2011 whose mother was imprisoned in pregnancy between 2000 and $2011(n=533)$ and children whose mother was imprisoned from birth to before age- 2 between 2001 and

Table 1 Observation periods for key analyses

\begin{tabular}{|c|c|c|c|c|c|}
\hline Aim/Analyses & $\begin{array}{l}\text { Maternal imprisonment observation } \\
\text { period }\end{array}$ & $\begin{array}{l}\text { Child birth } \\
\text { years }\end{array}$ & $\begin{array}{l}\text { Data observation } \\
\text { years }\end{array}$ & Prison group $n$ & Comparison group $n$ \\
\hline \multicolumn{6}{|c|}{ 1. Maternal incarceration exposure } \\
\hline In pregnancy & Pregnancy & $2001-2011$ & 2000-2011 & 533 & - \\
\hline In infancy & Birth to age $<2$ & $2001-2011$ & $2001-2013$ & 1199 & - \\
\hline \multicolumn{6}{|c|}{ 2. Child protection system contact } \\
\hline All children & Pregnancy to age $<2$ & $2001-2011$ & 2000-2017 & 1383 & 6714 \\
\hline \multicolumn{6}{|l|}{ 3. Infant mortality rates } \\
\hline All children & 5 -years pre-birth to age $<1$ & $2001-2011$ & 1996-2012 & 2180 & 6714 \\
\hline Indigenous children (Fig. 2) & 5-years pre-birth to age $<1$ & 1992-2011 & 1987-2012 & 2818 & 7190 \\
\hline
\end{tabular}


$2013(n=1199)$. There were 349 children within both groups who were exposed to maternal imprisonment in pregnancy and after birth before age-2. Mothers could have multiple children who met the inclusion criteria.

To address aim 2, child protection system contact was described from the start of pregnancy through to before age-2, as it is possible for child protection notifications to be raised for unborn children in Western Australia.

To address aim 3, we studied children born to mothers with a history of imprisonment 5-years before birth to age-1 $(n=2180)$ as infant mortality is a rare outcome in Australia and there were not sufficient numbers of infant deaths to limit analyses to children of mothers imprisoned in pregnancy and their first year. Accordingly, the analyses explore the population characteristics and mortality outcomes of children whose mothers have a history of imprisonment. Not all children in our defined at-risk group will be directly exposed to maternal imprisonment in utero or after birth. Infant mortality rates for Indigenous children born from 1992 onwards were calculated in order to illustrate the change in rates over time. A similar calculation was not possible for non-Indigenous children, due to small numbers. Western Australian birth data for population denominators are only available by Indigenous status from 1992 onwards (ABS, 2015).

The comparison groups were also stratified by Indigenous status and limited to children whose mothers never had a record in any Department of Justice data collection (including for community-based correctional orders) at any time during the period from 1985 to 2014. These groups were selected to describe the difference in child protection system contact and infant mortality between infants of women prisoners and infants within a general community sample with no maternal corrections history.

\section{Analyses \\ Maternal incarceration exposure}

The proportion of women prisoners who are pregnant was calculated from the total number of Western Australian women prisoners using Australian Prisoner Census data (ABS, 2016). As the Prisoner Census records the prison population on a single day (30 June) each year, the numbers of pregnant women in custody on 30 June annually were identified from the study data using mothers' prison reception and discharge dates and children's birthdates. Pregnancy start date was calculated as being nine months before child birth-month, as child birthdate was provided to month of birth only and gestational age was not available.

The prevalence of children whose mother was imprisoned during their infancy (birth to age 2-years) was calculated for Indigenous and non-Indigenous children born in Western Australia across the period of 2001 to 2011 using population birth data from the ABS (ABS, 2015). The number, length and nature of offence for maternal imprisonments during infancy, were described using child birth and death dates, mother prison reception and discharge dates, sentence type, and major offence type using the Australian and New Zealand Standard Offence Classification (Pink, 2011). Maternal imprisonments included both juvenile and adult sentenced offenders and remandees held in Western Australian prisons.

\section{Child protection system contact}

Child protection system contact was defined as any record within the Western Australian Department of Communities: Child Protection and Family Support database for reports made to the Department concerning a child's welfare, applications or orders for a child's protection, and periods of out-of-home care (including for respite care as well as child maltreatment).

The proportion and rate (per 1000) of children who had any child protection contact (including out-of-home care) was calculated for children whose mother had a record of imprisonment during pregnancy and/or from birth to age 2-years, and for those whose mother never had a corrections record. The proportion and rate of children who were placed in out-of-home care was also calculated.

\section{Infant mortality}

Infant mortality rate is commonly defined as "the number of deaths under one year of age occurring among the live births in a given geographical area during a given year, per 1000 live births occurring among the population of the given geographical area during the same year" (Organisation for Economic Co-operation and Development (OECD) 2006). All children within the study population were live-born. Infant mortality rates (per 1000) across the period 2001-2011 were calculated for children with a history of maternal imprisonment and children of mothers with no corrective services history stratified by Indigenous status.

Infant mortality rates were calculated for Indigenous children born from 1992 to 2011 using 6-year moving averages (e.g. 1992-1997, 1993-1998, etc.) and presented for children of mothers with an incarceration history, children of mothers with no history of corrective services contact, and for all Western Australian Indigenous children, the latter using ABS data.

\section{Indigenous status}

Indigenous status for children and mothers in the study populations was provided through the Derived Indigenous Status Flag variable generated by the WADLS using bestpractice algorithms, which assess individuals' Indigenous 
status across multiple data collections to enhance accuracy (Christensen et al., 2014).

\section{Offence type}

Major offence type is recorded in the Department of Justice data collections using the Australian and New Zealand Standard Offence Classification, which contains 16 Divisions classified according to the offence aim, use of violence, victim, seriousness and intent (Pink, 2011). For the present study, offence type were described in six categories: Offences against the person (Divisions 1-5); Theft and related (Divisions 6-8); Fraud and related (Division 9 and bribery offences); Drug (Division 10 and licit drug offences); Public order (Divisions 11-13 and 16); Traffic and related (Division 14, and driving under the influence of alcohol or other substance, dangerous or negligent driving offences); and Breach of justice procedures (Division 15).

\section{Socioeconomic status and geographical remoteness}

The Socio-economic Indexes for Areas Index of Relative Socio-economic Disadvantage (ABS, 2013) and the Accessibility/Remoteness Index of Australia (ABS, 2014) were used to describe infant's socioeconomic status and geographical remoteness of their place of residence at time of birth.

\section{Statistical analysis}

All statistical analyses were performed in Stata version 14.0 and stratified by Indigenous status. The analyses were undertaken to establish whether the study populations differed in terms of their key characteristics. Pearson's chisquare was used to assess the difference between study subpopulations' basic demographic characteristics including sex, socioeconomic status, and geographical remoteness. A log-binomial regression model was applied to the child protection and infant mortality data to obtain risk ratios for comparing children of women prisoners with children whose mothers had no corrections record (Knol, Le Cessie, Algra, Vandenbroucke, \& Groenwold, 2011; McNutt, Wu, Xue, \& Hafner, 2003; Robbins, Chao, \& Fonseca, 2002).

\section{Results}

\section{Descriptive characteristics of the study sub-populations}

Table 2 describes the basic demographic characteristics of the study populations. Within the Indigenous and nonIndigenous populations, there were no statistically significant differences $(p>.05)$ between the two maternal imprisonment history subgroups across all characteristics. Likewise, within each of the Indigenous and non-Indigenous populations, there were no significant differences with respect to the sex distributions of the groups of infants with maternal imprisonment histories to those with no maternal corrections

Table 2 Descriptive characteristics of the study sub-populations, by Indigenous status

\begin{tabular}{|c|c|c|c|c|c|c|}
\hline & \multicolumn{3}{|l|}{ Indigenous } & \multicolumn{3}{|l|}{ Non-Indigenous } \\
\hline & \multicolumn{2}{|c|}{ Maternal imprisonment } & \multirow{2}{*}{$\begin{array}{l}\text { No maternal } \\
\text { corrections }\end{array}$} & \multicolumn{2}{|c|}{ Maternal imprisonment } & \multirow{2}{*}{$\begin{array}{l}\text { No maternal } \\
\text { corrections }\end{array}$} \\
\hline & Pregnancy to $<2$ yrs & $\begin{array}{l}5 \text { yrs. before } \\
\text { birth }-<1 \text { yr }\end{array}$ & & Pregnancy to $<2$ yrs & $\begin{array}{l}5 \text { yrs. before } \\
\text { birth- }<1 \text { yr }\end{array}$ & \\
\hline & $\%$ & $\%$ & $\%$ & $\%$ & $\%$ & $\%$ \\
\hline \multicolumn{7}{|l|}{ Sex } \\
\hline Male & 50.2 & 50.4 & 52.4 & 50.8 & 51.3 & 48.0 \\
\hline Female & 49.8 & 49.6 & 47.6 & 49.2 & 48.7 & 52.0 \\
\hline \multicolumn{7}{|l|}{ Socioeconomic status } \\
\hline Most disadvantage, 0-20\% & 58.7 & 58.5 & 60.0 & 42.0 & 42.9 & 20.5 \\
\hline $21-40 \%$ & 21.7 & 22.4 & 21.3 & 22.7 & 21.3 & 23.2 \\
\hline $41-60 \%$ & 11.8 & 11.8 & 8.9 & 18.1 & 16.5 & 16.3 \\
\hline $61-80 \%$ & 4.6 & 4.7 & 7.0 & 9.6 & 11.6 & 22.6 \\
\hline Least disadvantage, $81-100 \%$ & 3.2 & 2.6 & 2.8 & 7.6 & 7.7 & 17.3 \\
\hline \multicolumn{7}{|l|}{ Geographical remoteness } \\
\hline Major cities & 59.1 & 59.1 & 32.2 & 81.9 & 81.5 & 70.6 \\
\hline Inner regional & 4.5 & 5.5 & 7.4 & 11.5 & 11.2 & 12.3 \\
\hline Outer regional & 13.4 & 15.3 & 16.9 & 5.3 & 5.7 & 10.1 \\
\hline Remote $^{a}$ & 11.0 & 9.6 & 20.4 & 1.4 & 1.6 & 7.0 \\
\hline Very remote ${ }^{a}$ & 12.0 & 10.5 & 23.2 & & & \\
\hline Infants (n) & 944 & 1283 & 2923 & 439 & 511 & 3791 \\
\hline
\end{tabular}


record. In both the Indigenous and non-Indigenous populations, infants with a history of maternal imprisonment had different distributions of socioeconomic status and geographical remoteness in comparison to infants with no maternal corrections history.

\section{Maternal incarceration exposure Pregnancy}

Between 2001 and 2011, 5.7\% of Indigenous and 4.0\% of non-Indigenous Western Australian female prisoners were pregnant while imprisoned. Over the same period 383 Indigenous (17.40 per 1000) and 150 nonIndigenous (0.49 per 1000) children were born to mothers who were imprisoned at least once while pregnant with them.

\section{Birth to two-years}

Table 3 provides a summary of children's exposure to maternal incarceration in infancy. In total, 804 Indigenous and 395 non-Indigenous children had a mother imprisoned at least once between their birth and their second birthday, equating to 36.52 per 1000 Indigenous and 1.29 per 1000 non-Indigenous children born in Western Australia between 2001 and 2011. Of these children, 30\% of Indigenous and 27\% of non-Indigenous, also had their mother imprisoned while pregnant with them.

For most children exposed to maternal incarceration between birth and age 2-years, their mothers were imprisoned just once (63\% Indigenous and $75 \%$ nonIndigenous children). The mean (SD) length of incarceration was 97 (184) days but the distribution was highly skewed, with half of all mothers' prison stays being for periods less than three-weeks with a median (IQR) of 19 (4-110) days.

The level of exposure varied considerably across the population of children exposed to maternal incarceration with $37 \%$ of Indigenous and $25 \%$ of non-Indigenous children experiencing multiple (up to 11) periods of maternal incarceration during infancy. For $22 \%$ of Indigenous and $23 \%$ of non-Indigenous children, their mother was imprisoned in total for more than a quarter of their life to age 2-years.

As shown in Table 3, mothers of children aged less than 2-years are more frequently imprisoned for nonviolent offences related to theft, breach of justice procedures, and traffic offences. Offences against a person (e.g., acts intended to cause injury) accounted for $29 \%$ of Indigenous and $17 \%$ of non-Indigenous mothers' imprisonments.

\section{Child protection system contact}

As shown in the Table 4, a considerably higher proportion of children had contact with the Western Australian child protection system by their second birthday if their mother was imprisoned during pregnancy or infancy, compared with children whose mother never had any involvement with corrective services.

For children born between 2001 and 2011 with a history of maternal imprisonment in pregnancy or infancy, 537 (568.9 per 1000) Indigenous and 243 (553.5 per 1000) non-Indigenous children came into contact with the child protection system by their second birthday. Of those children, 291 (31\%) Indigenous and 153 (35\%) non-Indigenous children were removed and placed in out of home care by age 2 .

In comparison to children whose mothers had no corrections involvement, children of mothers with a prison record in pregnancy or infancy were 8-times (RR 7.99; 95\%CI 6.93 to 9.22, $p<.001$ ) and 28-times (RR 28.36; $95 \%$ CI 22.29 to $36.08, p<.001$ ) more likely to have contact with the child protection system by age 2 years for Indigenous and non-Indigenous children respectively. Rates of placement in out-of-home care by age- 2 were 27-times (RR 27.30; 95\%CI 19.19 to $38.84, p<.001$ ) greater for Indigenous and 110-times (RR 110.10; 95\%CI 61.70 to $196.49, p<.001)$ greater for non-Indigenous children whose mothers had a prison history during pregnancy to age 2-years compared to children whose mothers had no contact with corrections.

For the children of mothers with a record of imprisonment in pregnancy or infancy who had no child protection contact by age 2-years, a further $23 \%$ Indigenous and $19 \%$ non-Indigenous had child protection contact after their second birthday. A further $8 \%$ of Indigenous and $7 \%$ of non-Indigenous children had spent time in out-of-home care. This compared with $18 \%$ Indigenous (2\% out-of-home care) and $4 \%$ non-Indigenous $(0.5 \%$ out-of-home care) for children of mothers with no record of corrections contact.

By the end of the observation period in 2017, 21\% of Indigenous and $26 \%$ non-Indigenous children with maternal imprisonment history in pregnancy or infancy had no child protection contact. This compares with $75 \%$ of Indigenous and $94 \%$ of non-Indigenous children of mothers with no corrections involvement.

\section{Infant mortality}

Across 2001-2011, Western Australian children whose mothers had a history of imprisonment prior to their birth (up to five years prior) or within their first year of life had an infant mortality rate of 22.6 deaths per 1000 Indigenous births and 7.8 deaths per 1000 nonIndigenous births. Infant mortality rates were higher for children of women prisoners compared to children of mothers who had no contact with corrective services by 2.36 -times (95\%CI 1.41 to $3.95, p=.001$ ) for Indigenous and 2.28-times (95\%CI 0.75 to $6.97, p=.147$ ) for nonIndigenous children. 
Table 3 Maternal incarceration exposure in infancy (birth to age 2-years) for Western Australian children born 2001-2011

\begin{tabular}{|c|c|c|c|c|}
\hline \multirow[b]{2}{*}{ Characteristics } & \multicolumn{2}{|c|}{ Indigenous } & \multicolumn{2}{|c|}{ Non-Indigenous } \\
\hline & $\mathrm{n}$ & $\%$ & $n$ & $\%$ \\
\hline \multicolumn{5}{|l|}{ Child experience of maternal incarceration } \\
\hline Mother imprisoned in infancy (not pregnancy) & 561 & 69.8 & 289 & 73.2 \\
\hline Mother imprisoned in infancy and pregnancy & 243 & 30.2 & 106 & 26.8 \\
\hline \multicolumn{5}{|c|}{ Number of maternal imprisonments in infancy, per child } \\
\hline 1 & 509 & 63.3 & 297 & 75.2 \\
\hline 2 & 170 & 21.1 & 65 & 16.5 \\
\hline 3 & 66 & 8.2 & 20 & 5.1 \\
\hline $4+$ & 59 & 7.3 & 13 & 3.3 \\
\hline \multicolumn{5}{|l|}{ Percentage of child's infancy mother was imprisoned } \\
\hline $0-5 \%$ & 428 & 53.2 & 202 & 51.1 \\
\hline $6-25 \%$ & 203 & 25.2 & 104 & 26.3 \\
\hline $26-50 \%$ & 114 & 14.2 & 70 & 17.7 \\
\hline $51-75 \%$ & 47 & 5.8 & 14 & 3.5 \\
\hline $76-100 \%$ & 12 & 1.5 & 5 & 1.3 \\
\hline \multicolumn{5}{|l|}{ Length of maternal prison stays ${ }^{a}$} \\
\hline Up to 2 weeks / 0-14 days & 620 & 46.7 & 234 & 43.0 \\
\hline 2-4 weeks / 15-30 days & 154 & 11.6 & 63 & 11.6 \\
\hline 1-3 months / 31-90 days & 186 & 14.0 & 80 & 14.7 \\
\hline 3-6 months / 91-180 days & 138 & 10.4 & 61 & 11.2 \\
\hline 6-12 months / 181-365 days & 147 & 11.1 & 68 & 12.5 \\
\hline Greater than 1 year / 366+ days & 82 & 6.2 & 38 & 7.0 \\
\hline \multicolumn{5}{|l|}{ Sentence type ${ }^{a}$} \\
\hline Unsentenced - remand & 683 & 51.5 & 265 & 48.7 \\
\hline Sentenced - default of fine & 250 & 18.8 & 91 & 16.7 \\
\hline Sentenced - other & 394 & 29.7 & 188 & 34.6 \\
\hline \multicolumn{5}{|l|}{ Offence type ${ }^{a b}$} \\
\hline Against the person & 361 & 29.3 & 87 & 16.6 \\
\hline Theft and related & 389 & 31.6 & 162 & 30.9 \\
\hline Fraud and related & 39 & 3.2 & 59 & 11.3 \\
\hline Drug offences & 12 & 1.0 & 45 & 8.6 \\
\hline Public order & 45 & 3.7 & 12 & 2.3 \\
\hline Traffic and related & 173 & 14.0 & 59 & 11.3 \\
\hline Breach of justice procedures & 213 & 17.3 & 100 & 19.1 \\
\hline
\end{tabular}

${ }^{\mathrm{a}} 1871$ maternal prison records in infancy (1327 Indigenous and 544 non-Indigenous)

${ }^{b} 115$ prison records missing offence type (95 Indigenous and 20 non-Indigenous)

Figure 1 shows the temporal change and difference in infant mortality rates between Indigenous children whose mother had a history of imprisonment and those whose mother had no corrections record, as well as the Western Australian average for Indigenous children. Between 1992 and 97 and 2006-11, infant mortality rates for Western Australian Indigenous children reduced by $56 \%$ overall and by $40 \%$ for children with maternal prison history, while there was less change in rates for children with no maternal corrections history with a $25 \%$ reduction over the period.

\section{Discussion}

A major finding of the study is that 1 in 3 children whose mothers were imprisoned during pregnancy or their first two years of life, were placed in out-of-home care by their second birthday. In contrast only 1 in 100 Indigenous and 1 in 300 non-Indigenous children whose 
Table 4 Child protection system contact before and after age 2 years, by maternal imprisonment history

\begin{tabular}{|c|c|c|c|c|c|c|c|c|}
\hline \multirow[b]{3}{*}{ Child protection contact } & \multicolumn{4}{|c|}{ Indigenous children } & \multicolumn{4}{|c|}{ Non-Indigenous children } \\
\hline & \multicolumn{2}{|c|}{ Maternal imprisonment } & \multicolumn{2}{|c|}{ No corrections record } & \multicolumn{2}{|c|}{ Maternal imprisonment } & \multicolumn{2}{|c|}{ No corrections record } \\
\hline & $\mathrm{n}$ & $\%$ & $n$ & $\%$ & $\mathrm{n}$ & $\%$ & $n$ & $\%$ \\
\hline Child protection contact by age- 2 & 537 & 56.9 & 208 & 7.1 & 243 & 55.4 & 74 & 2.0 \\
\hline Out-of-home care by age-2 & 291 & 30.8 & 33 & 1.1 & 153 & 34.9 & 12 & 0.3 \\
\hline No child protection contact by age- 2 & 407 & 43.1 & 2715 & 92.9 & 196 & 44.6 & 3717 & 98.0 \\
\hline Child protection contact age-2+ & 213 & 22.6 & 527 & 18.0 & 84 & 19.1 & 145 & 3.8 \\
\hline Out-of-home care age-2+ & 78 & 8.3 & 67 & 2.3 & 30 & 6.8 & 20 & 0.5 \\
\hline Total & 944 & 100 & 2923 & 100 & 439 & 100 & 3791 & 100 \\
\hline
\end{tabular}

mothers had never been in contact with corrective services were placed in out of home care by the same age. While parental imprisonment has been recognised as a factor that contributes to infants and children being placed in care (Delfabbro, Borgas, Rogers, Jeffrey, \& Wilson, 2009), the extent to which the population of women prisoners have children placed in care has not been previously quantified in Australia.

In our study, half of all imprisonments were for unsentenced mothers being held in custody on remand. In such circumstances it is possible mothers may not have time to arrange care for their children following their arrest (Healy, Foley, \& Walsh, 2001; Dallaire, 2007). Nearly half of all imprisonments of mothers whose children were aged less than 2 years were for two-weeks or less. This raises the question of if and how the length of a mother's prison stay impacts on the likelihood of child protection contact. Prisoners held on remand or for short periods would be difficult to capture in prospective research and so have not featured much in prior studies.

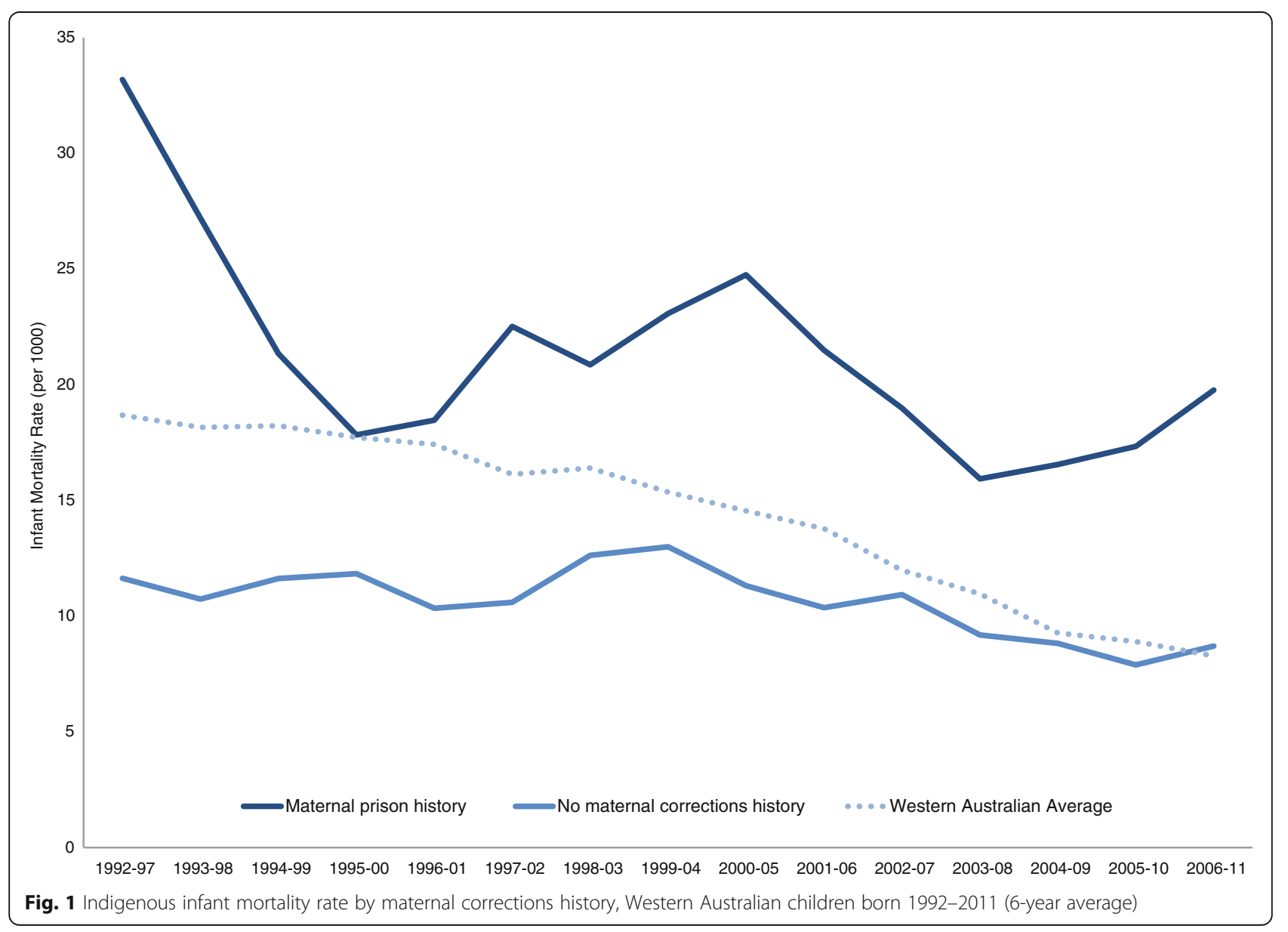


The assumption is often that longer periods of imprisonment are potentially more harmful for young children, as in theory they are more likely to lead to disrupted attachment. But it is possible that shorter imprisonments, and unplanned detention in the case of remandees, create a greater disruption for already vulnerable families. Questions have been raised about the utility of short-term imprisonment in general (Trevena, \& Weatherburn, 2015; Wermink, Blokland, Nieuwbeerta, Nagin, \& Tollenaar, 2010). The data reported in this study highlight the importance of considering the value of very short-term maternal imprisonments. Such periods are unlikely to allow for any participation in rehabilitative programs and may increase the likelihood of children coming into contact with the child protection system, although whether such contact is helpful or harmful to the child is not known.

One in six of the maternal imprisonments in the cohort were for non-payment of fines. While nearly a third of maternal imprisonments for the Indigenous population were for violent offences against the person, a significant number of imprisonments for both Indigenous and non-Indigenous mothers were for non-violent crimes and fine default. There was legislative action taken to reduce imprisonments for non-payment of fines in Western Australia in the mid-1990s with the enactment of the Fines, Penalties and Infringement Notices Enforcement Act 1994 (WA). This appeared to lead to a significant reduction in maternal imprisonments from 1994 to 1996 (Dowell et al. 2017), although the current study demonstrates that default of fine remains a common reason for imprisonment of Western Australian women prisoners with young children. The Western Australian legislation has since been described as having "a discriminatory and disproportionate effect, leading to the over-representation of Aboriginal and Torres Strait Islander peoples, poor people and vulnerable people, in the Western Australian prison system" (Law Society of Western Australia, 2016). Female prisoners are more frequently imprisoned for default of fine than male prisoners in Western Australia (Morgan, 2016). Three-quarters of women imprisoned for fine default in Western Australia are not employed, in comparison to $10 \%$ of males (Morgan, 2016). Socioeconomic factors including homelessness can also lead to prisoners being detained on remand in circumstances where they would otherwise be released before trial (Ayres, Heggie, \& de Almeida Neto, 2010). While it is well established that women prisoners experience high levels of socioeconomic disadvantage, the policy discussion around short term, remand, and fine default imprisonments has not extended to consider the potential implications of these for children with incarcerated mothers.

We found that for children aged less than 2 years, rates of contact with the child protection system were almost identical for Indigenous and non-Indigenous children whose mothers were imprisoned during pregnancy or before their second birthday. However, twice the number of Indigenous compared to non-Indigenous children had their mother imprisoned between pregnancy and their second birthday. This is of concern given that less than $7 \%$ of Western Australian children under 4 years old are Indigenous (ABS, 2011). The overrepresentation of Indigenous children within the child protection system has been well established (Delfabbro, Hirte, Rogers, \& Wilson, 2010). Our study findings raise the question of how much of the over-representation of young Indigenous children in the child protection system may be related to the over-representation of Indigenous women in the prison system. The removal of Indigenous children from families is a pertinent issue in Australia, with some commentators expressing concerns in the wake of the rise in numbers of Indigenous children in care (Lavarch, 2016).

It would be valuable to explore whether there is any association between the timing of maternal incarceration and child protection contact but this is beyond the scope of the present paper given the complexities we have reported of prison exposure in terms of frequency and duration, and taking account of similar complexities of the timing, frequency and nature of child protection system contacts, familial relationships and additional contributing factors. The magnitude of our findings suggest the interaction between maternal incarceration and exposure of children to the child protection system is significant. The relationship between maternal incarceration, child protection and juvenile justice system involvement is clearly an important area for future research.

Our study found that infant mortality rates for children of mothers with a history of imprisonment were over twice the rate for children of mothers with no corrections record. This equated to an additional 13.1 deaths per 1000 Indigenous births and 4.4 deaths per 1000 non-Indigenous births, for children whose mothers have a history of imprisonment. While we were unable to calculate rates for women imprisoned during pregnancy separately, the international literature on the birth outcomes of women imprisoned during pregnancy has found improved birth outcomes, including birth weight, for women imprisoned during pregnancy compared to women imprisoned at other times and worse birth outcomes compared to women who are never imprisoned (Knight, \& Plugge, 2005). However, these findings were not replicated by the only Australian study to date by Walker, Hilder, 
Levy, and Sullivan (2014), which found similarly poor birth outcomes for women imprisoned while pregnant compared to women imprisoned at other times. The authors questioned whether this was in part due to the shorter imprisonment terms within the New South Wales female prison population compared to those in the United States (Walker et al., 2014). Our findings highlight the increased risk of infant mortality for children born to mothers with a history of imprisonment. Further research is needed, however, to establish whether the experience of maternal incarceration itself increases children's infant mortality risk, or whether it is acting as a marker of extreme vulnerability.

\section{Limitations}

The sampling methodology for the broader longitudinal study, from which the data were drawn, primarily identified children whose mothers had at least one record of imprisonment after their birth to their 18th-birthday. While it was possible to identify women who were imprisoned while pregnant, the sample did not include a full census of women imprisoned during pregnancy in Western Australia. Possible implications of this would be an underreporting of the proportion of Western Australian female prisoners who are pregnant, however, we found similar proportions of female prisoners who are imprisoned while pregnant as Australian-wide data (Australian Institute of Health and Welfare, 2014). Thus any error is likely to be small.

Data were not available on gestational age and the day of birth, accordingly the date of commencement of pregnancy was taken as nine-months before the first day of a child's birth month. This may have included some mothers who were not yet pregnant at time of imprisonment, but were at least nine months away from giving birth. Research has shown, however, that the preconception period (approximately 6 months prior to conception) is also an important time when the experience of maternal stress during this period can impact on the health of the conceived child (Class, Khashan, Lichtenstein, Långström, \& D’Onofrio, 2013).

\section{Conclusions}

This is the first Australian study to report the extent of the population of infant children of women prisoners in contact with the child protection system. The results confirm that infant children of women prisoners are a highly vulnerable population who experience a significantly increased risk of engagement with the child protection system and placement in out-of-home care. These children also experience high rates of infant death compared to children of mothers with no corrective services history. The findings also demonstrate that many imprisoned mothers of young children are held on remand, for short periods of time and for non-violent crimes. This study highlights the importance of considering the heterogeneity of timing and frequency of imprisonment within the prison population on outcomes for families and children.

\section{Abbreviations \\ ABS: Australian Bureau of Statistics; COAG: Council of Australian Governments; OECD: Organisation for Economic Co-operation and Develop- ment; WADLS: Western Australian Data Linkage System}

\section{Acknowledgements}

We thank the Developmental Pathways in Western Australian Children Project, the Western Australian Data Linkage Branch, the Western Australian Aboriginal Health Research Ethics Committee, the Western Australian Aboriginal and Torres Strait Islander community, the Western Australian Department of Justice, the Department of Communities: Child Protection and Family Support, the Western Australian Department of Health and the custodians of the Western Australian Birth and Death Registrations, and Midwives Notification System for the linkages, provision of data and ongoing ethical review of project outputs.

Material presented cannot be considered as either endorsed by the Western Australian Department of Justice or an expression of the policies or view of the Department, and any errors or omission or commission are the responsibility of the Researchers.

Responsibility for interpretation of the data supplied through the Government of Western Australia, the Developmental Pathways in Western Australian Children Project, and by any other data custodian, is the Researchers' alone.

\section{Funding}

CD was funded by an Australian Government Research Training Program (RTP) Scholarship.

\section{Availability of data and materials}

This study used linked routinely-collected administrative data from the Western Australian Departments of Health, Justice, and Communities: Child Protection and Family Support. While these data are accessible to approved researchers through the standard ethical and data application processes, they are not publicly available and are maintained by the relevant government data custodians. As a result, while future researchers are able to apply directly for these data we are restricted under Statutory requirement from releasing any of our project data to a third party. This includes making the study data available in a publicly available repository.

\section{Authors' contributions}

$C D$ had primary responsibility for the study design, conduct of the data analysis and interpretation, and drafting the initial and final versions of the manuscript. LS, GM and DP contributed to study design, interpretation of findings and drafts of the manuscript. GM contributed to data analysis. All authors read and approved the final manuscript.

\section{Ethics approval and consent to participate}

Ethical approval for the project was received from the Department of Health Human Research Ethics Committee, the Western Australian Aboriginal Health Ethics Committee, and the University of South Australia Human Research Ethics Committee.

\section{Consent for publication}

The study uses data that is routinely collected by the Department of Justice and other Western Australian Government departments and services and linked for research purposes by the Western Australian Data Linkage Branch. In cases such as this the National Health and Medical Research Council outlines in the National Statement on Conduct in Human Research the requirements for waiver of consent. Under the National Statement, a Human Research Ethics Council can grant a waiver of consent if it is satisfied certain 
conditions have been met. The criteria for allowing a waiver listed under the National Statement apply to the project. Specifically as the project carries no more than a low risk; it is not feasible to obtain consent due to the age and quantity of the data required; and measures are being taken to ensure the continued protection of the confidentiality of the data.

\section{Competing interests}

The authors declare that they have no competing interests.

\section{Publisher's Note}

Springer Nature remains neutral with regard to jurisdictional claims in published maps and institutional affiliations.

\section{Author details}

${ }^{1}$ Health Economics and Social Policy Group, Centre for Population Health Research, Sansom Institute, School of Health Sciences, University of South Australia, GPO Box 2471, Adelaide, SA 5001, Australia. ${ }^{2}$ Centre for Health Services Research, School of Population and Global Health, University of Western Australia, Crawley, WA, Australia.

\section{Received: 3 August 2017 Accepted: 4 January 2018}

Published online: 15 January 2018

\section{References}

Aaron, L, Dallaire, DH. (2010). Parental incarceration and multiple risk experiences: Effects on family dynamics and children's delinquency. Journal of Youth and Adolescence, 39(12), 1471-1484.

Abbott, P, Magin, P, Hu, W. (2016). Healthcare delivery for women in prison: A medical record view. Australian Journal of Primary Health, 22, 523-529.

Australian Bureau of Statistics (ABS) (2011). Data Cubes, Estimated resident Aboriginal and Torres Strait Islander and Non-Indigenous population, States and Territories - 30 June 2011. http://www.abs.gov.au/AUSSTATS/abs@.nsf/ DetailsPage/3238.0.55.001 June\%202011?OpenDocument. Accessed 14 Jun 2017.

Australian Bureau of Statistics (ABS) (2013). Socio-Economic Indexes for Areas. http://www.abs.gov.au/websitedbs/censushome.nsf/home/seifa. Accessed 17 Nov 2017.

Australian Bureau of Statistics (ABS) (2014). Remoteness Structure. http://www. abs.gov.au/websitedbs/d3310114.nsf/home/remoteness+structure. Accessed 17 Nov 2017

Australian Bureau of Statistics (ABS) (2015). 3301.0 - Births, Australia, 2015. http:// www.abs.gov.au/ausstats/abs@.nsf/mf/3301.0. Accessed 14 Jun 2017.

Australian Bureau of Statistics (ABS) (2016). 4517.0 - Prisoners in Australia, 2016. http://www.abs.gov.au/ausstats/abs@.nsf/mf/4517.0. Accessed 14 Jun 2017.

Australian Institute of Health and Welfare (2014). The health of Australia's prisoners 2015. http://www.aihw.gov.au/WorkArea/DownloadAsset.aspx?id= 60129553682. Accessed 14 Jun 2017.

Ayres, S, Heggie, K, de Almeida Neto, A. (2010). Research Digest No. 4, Bail refusal and homelessness affecting remandees in NSW. Corrective Services NSW: http://www.correctiveservices.justice.nsw.gov.au/Documents/research-andstatistics/004-Research-Digest.pdf . Accessed 14 Jun 2017.

Brown, DW, Anda, RF, Tiemeier, H, Felitti, VJ, Edwards, VJ, Croft, JB, Giles, WH. (2009). Adverse childhood experiences and the risk of premature mortality. American Journal of Preventive Medicine, 37(5), 389-396.

Byrne, MW, Goshin, LS, Joestl, SS. (2010). Intergenerational transmission of attachment for infants raised in a prison nursery. Attachment \& Human Development, 12(4), 375-393.

Christensen, D, Davis, G, Draper, G, Mitrou, F, McKeown, S, Lawrence, D, McAullay, D, Pearson, G, Rikkers, W, Zubrick, SR. (2014). Evidence for the use of an algorithm in resolving inconsistent and missing indigenous status in administrative data collections. Australian Journal of Social Issues, 49(4), 423-443.

Class, QA, Khashan, AS, Lichtenstein, P, Långström, N, D'Onofrio, BM. (2013). Maternal stress and infant mortality: The importance of the preconception period. Psychological Science, 24(7), 1309-1316.

Council of Australian Governments (COAG) (2009). Closing the gap on indigenous disadvantage: The challenge for Australia, February 2009. Commonwealth of Australia: https://www.dss.gov.au/sites/default/files/documents/05_2012/ closing_the_gap.pdf. Accessed 16 Nov 2017.

Council of Australian Governments (COAG) (2016). Closing the gap prime Minister's report 2016. Commonwealth of Australia: https:/www.pmc.gov.au/sites/default/ files/publications/closing_the_gap_report_2016.pdf. Accessed 16 Nov 2017.
Dallaire, DH. (2007). Incarcerated mothers and fathers: A comparison of risks for children and families. Family Relations, 56, 440-453.

Dallaire, DH, Zeman, JL, Thrash, TM. (2015). Children's experiences of maternal incarceration-specific risks: Predictions to psychological maladaptation. Journal of Clinical Child and Adolescent Psychology, 44(1), 109-122.

Delfabbro, P, Borgas, M, Rogers, N, Jeffrey, H, Wilson, R. (2009). The social and family backgrounds of infants in south Australian out-of-home care 20002005: Predictors of subsequent abuse notifications. Children and Youth Services Review, 31, 219-226.

Delfabbro, P, Hirte, C, Rogers, N, Wilson, R. (2010). The over-representation of young aboriginal or Torres Strait islander people in the south Australian child system: A longitudinal analysis. Children and Youth Services Review, 32, 1418-1425.

Dennison, S, Stewart, A, Freiberg, K. (2013). A prevalence study of children with imprisoned fathers: Annual and lifetime estimates. Australian Journal of Social Issues, 48(3), 339-362.

Department of Corrective Services (2009). Profile of women in prison 2008: final report. Government of Western Australia: https://www.correctiveservices.wa. gov.au/_files/about-us/statistics-publications/students-researchers/profilewomen-prison-2008-final.pdf . Accessed 14 Jun 2017.

Dowell, CM, Preen, DB, Segal, L. (2017). Quantifying maternal incarceration: A whole population linked data study of western Australian children born 1985-2011. Australian and New Zealand Journal of Public Health, 41(2), 151-157.

Fines, Penalties and Infringement Notices Enforcement Act 1994 (WA)

Friestad, C, Ase-Bente, R, Kjelsberg, E. (2012). Adverse childhood experiences among women prisoners: Relationships to suicide attempts and drug use. International Journal of Psychiatry, 60(1), 40-46.

Healy, K, Foley, D, Walsh, K. (2001). Families affected by the imprisonment of a parent: Towards restorative practices. Children Australia, 26(1), 12-19.

Heindel, JJ, \& Vandenberg, LN. (2016). Developmental origins of health and disease: A paradigm for understanding disease etiology and prevention. Current Opinion in Pediatrics, 27(2), 248-253.

Holman, CD, Bass, AJ, Rouse, IL, Hobbs, MS. (1999). Population based linkage of health records in Western Australia: Development of a health services research linked database. Australian and New Zealand Journal of Public Health, 23(5), 453-459.

Knight, M, \& Plugge, E. (2005). The outcomes of pregnancy among imprisoned women: A systematic review. BJOG: An International Journal of Obstetrics \& Gynaecology, 112, 1467-1474.

Knol, MJ, Le Cessie, S, Algra, A, Vandenbroucke, JP, Groenwold, RHH. (2011). Overestimation of risk ratios by odds ratios in trails and cohort studies: Alternatives to logistic regression. Canadian Medical Association Journal, 184(8), 895-899.

Latendresse, G, Wong, B, Dyer, J, Wilson, B, Baksh, L, Hogue, C. (2015). Duration of maternal stress and depression: Predictors of newborn admission to neonatal intensive care unit and postpartum depression. Nursing Research, 64(5), 331-341.

Lavarch, M. (2016, October 8). Australia must act now to prevent a new Stolen Generation tragedy. The Guardian. https://www.theguardian.com/australianews/2016/oct/08/australia-must-act-now-to-prevent-a-new-stolengeneration-tragedy. Accessed 14 Jun 2017.

Law Society of Western Australia (2016). Briefing paper: Imprisonment of fine defaulters. Law Society of Western Australia: https://www.lawsocietywa.asn. au/wp-content/uploads/2015/10/Law-Society-Briefing-Papers-Imprisonmentof-Fine-Defaulters.pdf . Accessed 14 Jun 2017.

Maclean, MJ, Taylor, CL, O'Donnell, M. (2016). Pre-existing adversity, level of child protection involvement, and school attendance predict educational outcomes in a longitudinal study. Child Abuse \& Neglect, 51, 120-131.

McNutt, LA, Wu, C, Xue, X, Hafner, JP. (2003). Estimating the relative risk in cohort studies and clinical trials of common outcomes. American Journal of Epidemiology, 157(10), 940-943.

Morgan, N (2016). Fine defaulters in the Western Australian prison system. Government of Western Australia: Office of the Inspector of Custodial Services: http://www.parliament.wa.gov.au/publications/tabledpapers.nsf/ displaypaper/3914182a267c7268541194a448257fd20032c2e4/\$file/4182.pdf . Accessed 14 Jun 2017

Murray, J, Bijleveld, CCJH, Farrington, DP, Loeber, R. (2014). Effects of parental incarceration on children: Cross-national comparative studies. Washington, DC: American Psychological Association.

Organisation for Economic Co-operation and Development (OECD) (2006). Glossary of statistical terms: Infant mortality rate. OECD: https://stats.oecd.org/ glossary/detail.asp?|D=1347. Accessed 14 Jun 2017.

Osborn, AL, Delfabbro, P, Barber, JG. (2008). The psychosocial functioning and family background of children experiencing significant placement instability in Australian out-of-home-care. Children and Youth Services Review, 30, 847-860. 
Pink, B. (2011). Australian and New Zealand standard offence classification (ANZSOC), Australia, 2011 (Third edition). Australian Bureau of Statistics: http:// www.abs.gov.au/ausstats/abs@.nsf/mf/1234.0 . Accessed 14 Jun 2017.

Poehlmann, J. (2005). Representations of attachment relationships in children of incarcerated mothers. Child Development, 76(3), 679-696.

Reidpath, DD, Allotey, P. (2003). Infant mortality rate as an indicator of population health. Journal of Epidemiology and Community Health, 57, 344-346.

Robbins, AS, Chao, SY, Fonseca, VP. (2002). What's the relative risk? A method to directly estimate risk ratios in cohort studies of common outcomes. Annals of Epidemiology, 12(7), 452-454.

Rud, I, Van Klaveren, C, Groot, W, Maassen van den Brink, H. (2014). The externalities of crime: The effect of criminal involvement of parents on the educational attainment of their children. Economics of Education Review, 38, 89-103.

Trevena, J., \& Weatherburn, D. (2015). Crime and justice bulletin, contemporary issues in crime and justice number 187, does the first prison sentence reduce the risk of further offending? NSW Bureau of Crime Statistics and Research: http://www. bocsar.nsw.gov.au/Documents/CJB/Report-2015-Does-the-first-prison-sentencereduce-the-risk-of-further-offending-cjb187.pdf . Accessed 14 Jun 2017.

Walker, JR, Hilder, L, Levy, MH, Sullivan, EA. (2014). Pregnancy, prison and perinatal outcomes in new South Wales, Australia: A retrospective cohort study using linked health data. BMC Pregnancy and Childbirth, 14, 214.

Wermink, H, Blokland, A, Nieuwbeerta, P, Nagin, D, Tollenaar, N. (2010). Comparing the effects of community service and short-term imprisonment on recidivism: A matched samples approach. Journal of Experimental Criminology, 6(3), 325-349.

Wildeman, C. (2012). Imprisonment and infant mortality. Social Problems, 59(2) 228-257.

Wildeman, C, Andersen, SH, Lee, H, Karlson, KB. (2014). Parental incarceration and child mortality in Denmark. American Journal of Public Health, 104(3), 428-433.

\section{Submit your manuscript to a SpringerOpen ${ }^{\circ}$ journal and benefit from:}

- Convenient online submission

- Rigorous peer review

- Open access: articles freely available online

- High visibility within the field

- Retaining the copyright to your article

Submit your next manuscript at $\boldsymbol{s p r i n g e r o p e n . c o m ~}$ 